Heather Lea Moulaison - University of Missouri, School of Information Science \& Learning Technologies

Felicity Dykas - University of Missouri, Ellis Library

John M. Budd - University of Missouri, School of Information Science \& Learning Technologies

\title{
The Author and the Person: A Foucauldian Reflection on the Author in Knowledge Organization Systems
}

\begin{abstract}
Based on Foucault's exploration of the author-function, the current study investigates knowledge organization systems' treatment of persons. FRBR and FRAD do well to extend the information in library authority records beyond the personal name as a character string to include attributes of the person, yet aspects of the person as an author and of her author-function are still lacking. This paper briefly compares RDA/MARC and other current initiatives, and finds that Europeana, AustLit, The American Civil War: Letters and Diaries, and DBpedia all have the potential to record both attributes and relationships in authority records for persons. We conclude that additional attributes, relationships, and the previously unused category of events are pivotal to moving toward more Foucault-friendly KOSs in libraries.
\end{abstract}

\section{Introduction}

The question of how author data should be compiled and made available in controlled vocabulary systems and in knowledge organization systems (KOSs) is the subject of current interest in the knowledge organization (KO) community. IFLA's Functional Requirements for Bibliographic Records (FRBR) (1998) designates entities in the bibliographic universe; it also demonstrates relationships between entities. The sibling document, Functional Requirements for Authority Data (FRAD) (2009), builds on FRBR and designates fourteen attributes that can be recorded in authority records for persons, a Group 2 entity. These attributes are: 1) Dates associated with the person; 2) Title of the person; 3) Gender; 4) Place of birth; 5) Place of death; 6) Country; 7) Place of residence; 8) Affiliation; 9) Address; 10) Language of person; 11) Field of activity; 12) Profession/occupation; 13) Biography/history; and 14) Other information. Persons identified by the headings and described by the attributes are, according to FRBR, associated with Group 1 entities: works, expressions, manifestations, and/or items. In the bibliographic universe, people create [have relationships with] works, have attributes, and are represented by a character string (their name) that serves as a heading, yet they are never specifically identified as authors.

The complexities of authorship indicate that authors are not only persons and creators or contributors to Group 1 entities, but they are also producers of intellectual products: texts (Wilson, 2012). The author, her text, and that text's impact on the scholarly community are part of a larger context that extends beyond the current reach of the bibliographic universe as defined in FRBR, since aspects of the person as a writer extend beyond the attributes identified in FRAD.

This paper extends the Foucauldian inquiry into authorship in KOSs, continuing Budd and Moulaison's (2012) work on the topic. It also addresses issues first raised by Smiraglia, Lee, and Olson (2011) when they asked, "What role does the name of an author represent in the interplay between publishing, bibliography, and cataloging?" (p. 
137). We will examine the relationship between the information recorded and retained for authors in KOSs and the information required to support a comprehensive understanding of the author-function. Foucault's analysis of the complexities of the author-function and authorship are examined first. Next, we look to the literature in KO and Library and Information Science (LIS) to explore concepts related to authorship and authority records. We then discuss and compare current systems as they stand, and end with recommendations for rendering KOSs more amenable to representing authors, and subsequently allowing for the establishment of the author-function through the addition of information about events.

\section{Foucault: What is an author?}

Foucault responded to Roland Barthes's essay, "The Death of the Author" in his 1969 essay, "What Is an Author?" (published in 1977). Barthes (1977) preceded Foucault by saying that the author can no longer be considered a meaningful construct because, "for the good reason that writing is the destruction of every voice, of every origin. Writing is that neutral, that composite, that oblique space where our subject slips away, the negative where every identity is lost, starting with the identity of the very body which writes" (p. 142). Barthes's goal in the essay was effectively to replace "the Author" (as the primary creative signifier) with writing (or the process of creation rather than what he saw as an arbitrary creator (see Wilson, 1999, p. 340). Barthes's effort to replace the Author with writing - and thus to privilege writing as both act and product - caught Foucault's attention and led him to attempt a correction of Barthes's thinking. What may be most revolutionary about Barthes's short essay is his utter replacement of the author with the reader. In large part, he attempted to close down an entire school of literary criticism by shifting attention so completely: "a text's unity lies not in its origin but in its destination" (p. 142). The position is extremeto be useful for readers or to those who would seek to classify works.

In his essay Foucault (1977) asks: "What, in short, is the strange unit designated by the term, work? What is necessary to its composition, if a work is not something written by a person called an 'author'?" (p. 118). Foucault (1977) actually anticipated many of the challenges that would eventually arise in the field of $\mathrm{KO}$ as he diminished the "noun" that has been taken to signify an author and replace that inadequate speech act with "name" as classification (p. 123). In other words, the name attributed to a work, while imminently important both to reading and to categorization, has traditionally been removed from the human being attached to works. What is much more important is a completely revised conception of "authority." The authority no longer exists solely within the realm of a person which has been connected to a work. Greater attention must be paid to the discourse that is enabled by the work. The Author is transformed into the "author," or, more appropriately, the site of the author-function. As Foucault (1977) wrote, "We can conclude that, unlike a proper name, which moves from the interior of a discourse to the real person outside who produced it, the name of the author remains at the contours of texts-separating one from the other, defining their form, and characterizing their mode of existence" (p. 123).

\section{Complexities of Identity}


Foucault's author-function extends beyond the attributes of a person, a human being who lives in a certain place at a certain time and who has other identifiable attributes that can be recorded as authority data in an authority record. A particular example of Foucault's expansion of the author-function can be illustrated by using Sigmund Freud. Freud, of course, was an author of definable and attributable works. The discourse surrounding Freud, though, extends beyond the person or the proper name. Freud gave birth (intentionally or not) to Freudianism, or discursive practice that draws in some ways from his works. He also gave birth to psychoanalysis, a school of psychiatric and psychological practice. Psychoanalysts might or might not be Freudians, but they all either draw from or react against Freud and his works. Particular individuals are also connected to Freud; Otto Rank would be one such person. There are also individuals that have complex connections to Freud, such as Carl Jung. Jung and Freud are also responsible for works on dreams, but Jung departed from Freud's orthodoxy. Freud has further given rise to those who have reacted against his works and expressions including Betty Friedan. As Foucault (1977) remarks, authors who can be seen as embodying author-functions, such as Freud, are "'initiators of discursive practices,' [who] not only made possible a certain number of analogies that could be adopted by future texts, but, as importantly, they also made possible a certain number of differences" (p. 132).

\section{Review of the Literature}

In this brief review of the literature, we focus on the related concepts of authorship and authority records as a potential means for supplying information about authors. The principle of authorship has guided the field of librarianship in its work to organize information, and the implementation of name authorities has permitted the practical retrieval of surrogates in KOSs. One way to provide further information about authors that would help clarify aspects of the author-function is through the addition of information about possible influences on the authors, be they human (positive or negative), geographic, situation-based events, or other.

\section{Authorship}

The principle of authorship is pivotal to the design and use of KOSs (Smiraglia, Lee, \& Olson, 2011). In speaking of the creation and diffusion of knowledge, authors "facilitate discourse" (Smiraglia \& Lee, 2012, p. 36) and accordingly, are essential components of surrogate records describing works. In the modern tradition, the author is "in the narrower sense, [...] the person who writes a book; in a wider sense it may be applied to him who is the cause of the book's existence [....]" (Cutter, 1904, p. 14). Authors, therefore, exercise an essential function in the creation of a work, and in the Western tradition, are credited in the bibliography (Smiraglia, Lee, \& Olson, 2011).

The concept of authorship may be evolving at present (see Smiraglia \& Lee, 2012), especially given the collaborative environment that the web represents. It is also possible to imagine limited situations where users are seeking specific information and where in those instances, the author of the content retrieved may not matter (Svenonius, 2000). Given the evolution of circumstances for the creation of works and the information needs of a broader variety of users, the concept of authorship is one that continues to be addressed in KO and LIS. 


\begin{abstract}
Name Authorities
Information about people who are either authors (Group 2 entitles) or subjects (Group 3 entities) is retained in the KOS in a complementary database, the authority file. Authority files contain records about individuals playing a role in the bibliographic universe and are able to be consulted by employees in the creation of surrogate records. Name authority work "provides a preferred from of name with cross-references to different forms and related names" (Burke \& Shorten, 2013, p. 365), with the assumption that the name itself might change over time. To facilitate changes in names, non-text-based (presumably numerical) identifiers have been proposed as a complement to the traditional name-based but perpetually-updating headings entered into surrogates (Niu, 2013). VIAF, the Virtual International Authority File, provides unique identifiers that could be used in this way (Niu, 2013); VIAF also supplies URIs for name authority records (VIAF, 2013), potentially allowing VIAF records to become part of the linked data web.

Increasing the ease with which authority records are updated, disseminated, and used is crucial, but if the information housed in the authority record cannot be used efficiently in the search process, it will not benefit the end-user in the long run. Yee (2005) warns of the issues that arise in doing a keyword search for Samuel Clemens and Tom Sawyer in the online library catalog if the authority record for Mark Twain is not also searched as part of the query. In the library context, the contents of the records serves to help in the creation of the bibliographic record and for searching the name in the system, based on the authorship principle.
\end{abstract}

\title{
Analysis of Current Initiatives
}

Current projects and initiatives implement and expand the ideas of authorship presented in the FRBR and FRAD models. The projects listed below are geared toward providing identifying and contextual information for FRBR Group 2 entities and relationships between entities. Individually these records will not present a comprehensive picture, but through associations with other databases, linkages between co-authors, works, grants, institutions, interests, etc., can be created. Additional metadata, particularly terms and IDs that specify relationships will be needed to realize the author-function as described by Foucault. Table 1, available as an appendix to the paper on the web, demonstrates the examples raised in the discussion below (https://mospace.umsystem.edu/xmlui/handle/10355/10082/)

\section{Selected Standards}

The library community has been using cataloging code (AACR2 until 2013) along with the encoding standard MARC (MAchine Readable Cataloging) to encode library data for a generation. RDA (Resource Description and Access) represents an expansion on that tradition through its basis on the FRBR model, and MARC has been adapted to accommodate new needs presented as well.

RDA (Resource Description and Access). RDA (2010), as based on FRBR and FRAD, clarifies and delineates relationships between bibliographic entities and defines attributes for Group 2 entities. RDA "moves beyond what is required for an access 
point and toward a record for the person" (Oliver, 2010, p. 60). The relationships identified are geared toward the bibliographic relationships traditionally provided in catalog/bibliographic records, but cover a broader range of associations and greater specificity and consistency in delineating the nature of the relationship. RDA, Appendix I identifies terms for relationships between a resource and persons, families, and corporate bodies associated with the resource, and Appendix $\mathbf{J}$ identifies terms for relationships between works, expressions, manifestations, and items. Some derivative relationships provide linkages among entities in bibliographic families. This is especially true for written expressions that have been adapted as performances. In libraries, authority records with the new RDA attributes are available in the Library of Congress Name Authority File; these records also are included in VIAF.

MARC (MAchine Readable Cataloging). The encoding standard, MARC allows for the encoding of content and data, and it also serves as a content standard in its own right for some of the fields/fixed fields it proposes. Content added in these elements goes beyond content required by the cataloging codes in use, and help the system with storage and permit additional retrieval and collocations of items. MARC field tags map precisely to the FRAD attributes (see Table 1 online: https://mospace.umsystem.edu/xmlui/handle/10355/10082/) for personal names. Fields exist supporting all fourteen attributes, including dates, titles, other attributes, places, field of activity, group associations, occupation, language, and biographical data.

\section{Selected Projects}

The following projects are innovative in their use of authority data to drive organization, search, and retrieval. Comparisons among these databases and between FRAD and MARC 21 are also available in Table 1 online https://mospace.umsystem.edu/xmlui/handle/10355/10082/.

Europeana. Europeana (http://www.europeana.eu/) retains information similar in scope to FRAD, with a few notable differences. Similarities include the ability to record attributes such as dates, occupation, gender, and biography. One difference is that the encoding of the Europeana data model is linked data friendly, and information can be accessed as linked data. Another difference is the potential for the presence in the Europeana data model of information about relationships and events: hasMet; isRelatedTo; wasPresentAt . See Table 1 online (https://mospace.umsystem.edu/xmlui/handle/10355/10082/) for these and other fields used in Europeana. These person- and event-based potential influences permit a more robust contextualizing of the author-function based on the additional (non-attribute) information supplied.

AustLit. AustLit, the Australian Literature Resources (http://austlit.edu.au/), implemented the FRBR model to describe literary and creative works. Data included in authority records includes author attributes and relationships. Like Europeana, these relationships include such things as Influence-Agent and Influence-Work. Along with these, AustLit also includes FRAD attributes, including dates, other attributes, 
affiliation, occupation, gender, language, and biography. See Table 1 online (https://mospace.umsystem.edu/xmlui/handle/10355/10082/) for additional information.

The American Civil War: Letters and Diaries. This product, available via Alexander Street Press, is a subscription database allowing access to diaries, letters, and memoirs of individuals impacted by the American Civil War. The advanced search feature permits users to search specific attributes of authors, including their age when writing, race, religion, military rank, as well as the schools they attended (see Figure 1). Dropdown menus permit users to search with the controlled vocabularies values appropriate to each field. See $\quad$ Table 11 online (https://mospace.umsystem.edu/xmlui/handle/10355/10082/) for a more complete set of attributes and relationships permitted.

Figure 1. Advanced search options, The American Civil War: Letters and Diaries classification

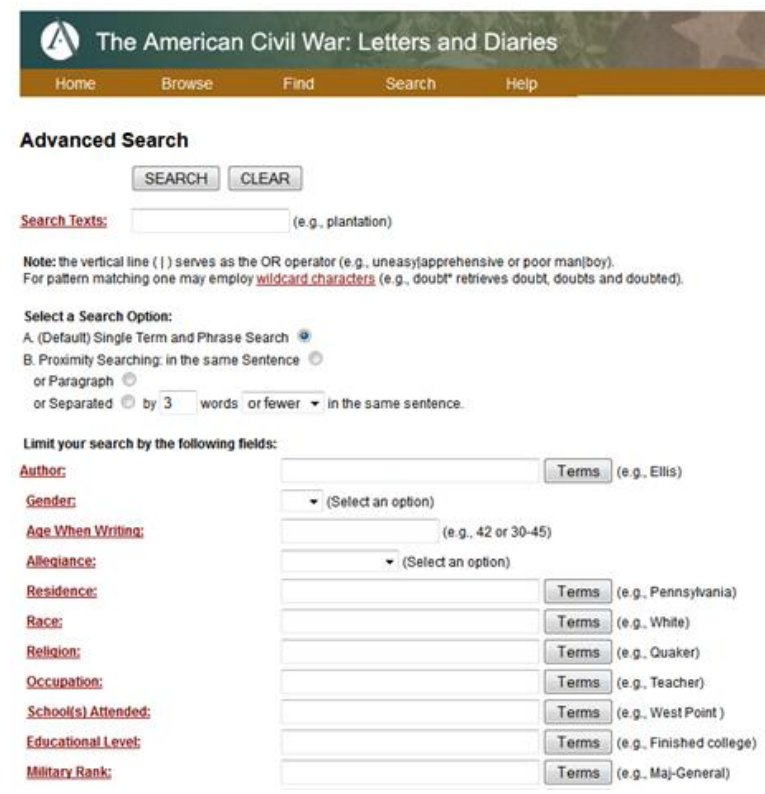

DBpedia. DBpedia (http://wiki.dbpedia.org/About), the linked data version of Wikipedia (About/News, 2013), maintains all of the information that FRAD indicates be recorded as attributes as well as a variety of additional attributes that KOSs have not traditionally retained. These attributes may not be scholarly across the board, and it is hard to imagine how the bust size, astrological sign, or tattoos of an author might impact her authorship. See Table 1 online https://mospace.umsystem.edu/xmlui/handle/10355/10082/) for more information. These attributes along with additional information about influences, sexual orientation, ideologies, and others might help not only understand the author in context, but lay the groundwork for thinking about the author-function.

\section{Discussion}


Access to the work has traditionally been the focus of KOSs. Cutter's Rules for a Dictionary Catalog (1904) describe principles for access, or Objects, focusing on the work. Cutter outlines tasks pertaining to the finding function (permitting users to find a surrogate for a work if author, title, or subject is known), the collocation function (bringing together works by author, subject or some other feature), and the selection function (permitting users to understand if the book will be useful based on information about the item). These Objects are the basis for current catalog systems, and underlie FRBR's approach to user tasks (see Tillett, 2003). Is there little doubt that, in a system dedicated to bibliographic records, the book would be the central focus?

With the focus on access to information about the book and its features, access to information about the author historically has been overlooked. In the traditional KOS used in libraries, information about attributes of authors has been and remains hidden from patrons. Lists of subject headings were made available to library patrons in the form of the Big Red Books (aka the Library of Congress Subject Headings), but access to detailed information about authors has not traditionally been part of the user experience. This is not to imply that authors are completely without importance in traditional KOSs. Main entries and primary access points are, according to cataloging rules, based on the author. It is generally the Greeks who are credited with shifting the focus of interest to the individual, and the importance of this aspect is maintained in the use of authors as entries in bibliographies. Some of the importance of the author in the traditional KOS is lost in the fact that he is reduced to a name - a character string that can be collocated with identical character strings. Systems with authority records created using AACR2 only have information about the author as it pertains to the choice of the character string that forms the heading.

FRBR and FRAD expand on the notion of author-as-character-string, adding information about the author as a person. The fourteen attributes identified in FRAD provide enriched authority records for use in KOSs and take an author from being a character string to becoming a more three-dimensional individual with the characteristics (attributes) of a person. Increased information about the author that can be leveraged to carry out searches in future KOSs is a great benefit to users and is indisputability an improvement over the previous name-only methods. Information about attributes and about relationships, identified separately in Table 1, goes a long way toward making personal name records reflect the person-ness of the authors they represent. They are less able, however, to indicate how those attributes and relationships were engendered if they were the result of an event in the author's life.

\section{The Author-Function and Events}

Based on our understanding of Foucault and the author-function, FRBR and FRAD do not go far enough in permitting users to understand an author in light of her authorfunction and to collocate (works, authors, movements, etc.) based on that authorfunction. Extending farther still, beyond the author-function, there is content pertaining to authors (and even to people) that can and should be included in authority records. This additional content, going beyond documentation of a choice of entry terms for a personal name heading as well as going beyond the fourteen additional attributes designated by FRAD, would allow library KOSs to be searched in a more robust manner. 
Scenarios that involve the selection of works based on criteria of authorship are easy to imagine. Researchers could examine books on a topic that were authored by 20 year-olds versus 70-year-olds. Information about age at the time of publication would need to be included in the authority records in library KOSs for this to happen in FRBR-compliant systems. Researches could also want to read all of the works written by members of a particular group, such as the Bloomsbury Group from England in the 1920s or by authors who frequented a certain French salon as the Enlightenment took shape.

Figure 2. Barbara Walters's participation in events, professional work, and personal relationships (http://mapper.nndb.com/start/?id=23371)

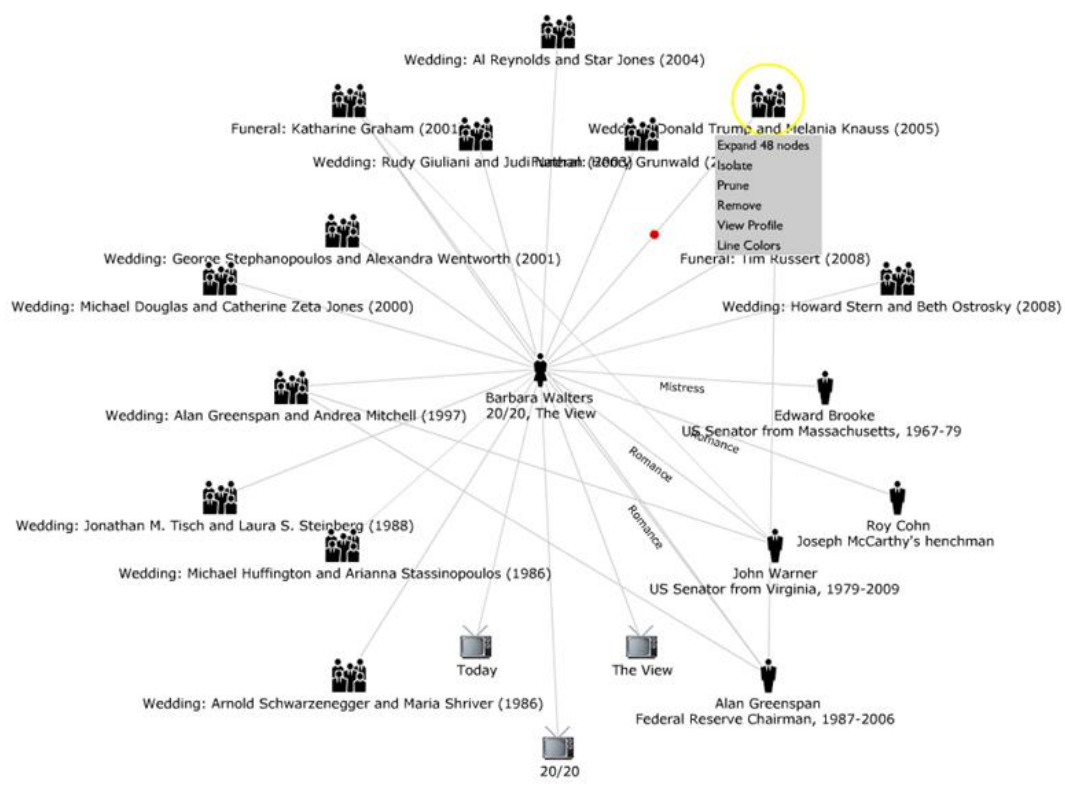

Events, in particular, can be defining aspects of an author's life, bringing about changes in relationships and statuses. An example of an event could be a wedding. By virtue of the marriage, the participants change their statuses from single to married. They also enter into new relationships with another person. Attendees at events also have the potential to be marked by it - they may meet future marriage partners at a wedding; they may also meet people in passing who do not, ultimately, affect their attributes or relationships. The interactions at events have the potential to influence persons, providing fodder for a fictionalized account of the events in the form of a work, or by overhearing conversations that influence thinking on, for example, a work in progress. Of the selected projects described above, only Europeana is considering implementing information about events to be recorded in authority records. Europeana will do this through the wasPresentAt element.

Linked data projects have been exploring the importance of events already with some success. For example, in NNBD Mapper (http://mapper.nndb.com/), Barbara Walters's participation in gala events can be traced, and moments when she overlapped with other stars can be assessed, with appropriate visualizations supporting the 
interactions (http://mapper.nndb.com/start/?id=23371) See Figure 2 for a visualization of Barbara Walters's participation in events, along with professional work and personal affiliations.

Events can be a defining factor in the life of any person, including an author. One way to record information about authors that would support an understanding of the author-function would be to record information about events in which she participated. This information would be recorded as well as attributes she possesses and relationships she has had, even if these attributes and relationships were attained as a result of participation in events. Being able to create a bibliographic network of events permits users to search more and better content about the context of authors.

\section{End-User Searching}

No matter the sophistication of an authority file's records, content will remain hidden until KOSs permit the kind of targeted retrieval that The American Civil War: Letters and Diaries permits with its advanced search's series of drop-down menus (see Figure 1). We suggest that the first step to ensuring robust access to works via sufficient information about their authors is to begin to include the kinds of attribute and relationship data that appear in DBpedia records and event data that appear in Europeana records for individuals in the authority records in our KOSs. The necessary second step is to permit retrieval based on that data.

\section{Conclusion}

Works are created by persons (or corporate bodies) in the FRBR model; persons create, yet, in doing so, the person becomes an author who is associated with a context extending beyond his or her person-ness. The author-function as described by Foucault goes beyond the contextualization of entities in the bibliographic universe to include aspects of the person as an author.

In the past, the KOS author was not a person, he was a character string in a database. This weakness is being overcome in FRBR/FRAD, which include fourteen attributes of persons in records for authors. DBpedia permits many more kinds of attributes than FRAD's fourteen to be recorded in a person's record, thereby potentially giving a fuller perspective on the person as well as potentially allowing for retrieval of works based on attributes of authors. All four of the projects examined in this paper, Europeana, AustLit, American Civil War: Letters and Diaries, and DBpedia permit both attributes and relationships to be recorded in the authority record. These projects serve as examples of what the FRBR model could permit library-based KOSs to do if relationship information were recorded in the authority records.

Europeana is the only KOS envisioning the inclusion of information about events in authority records for individuals. It is this final aspect that has the potential to make Europeana more Foucault-friendly than the other projects and the standards that were examined. This paper therefore makes a case for the inclusion not only of attributes in authority records, but also for the inclusion of information on relationships and events in those same records. To best make use of this additional data, it strongly encourages KOSs to implement retrieval systems that are robust enough to permit users to search for works within the context of the author, going beyond a simple search on a character string that is the author's name heading in the body of the bibliographic record. 


\section{References}

About/News. (2013). DBpedia. Retrieved from http://dbpedia.org/About.

American Library Association. (2010). RDA toolkit. Chicago, Ill: American Library Association.

Austit: Australian literary database. (2001). AustLit. Canberra, A.C.T.: Academy Library, UNSW@ADFA Retrieved from http://austlit.edu.au/

AustLit Fields. (n.d.). AustLit. www.austlit.edu.au/help/austlitFields.xml

Barthes, R. (1977). Image - Music - Text, trans. By S. Heath. London: Fontana/Collins.

Budd, J. M., \& Moulaison, H. L. (2012). Foucault and the bibliographic universe: What really is an author? Poster presented at the ASIST 2012 Annual Meeting, October 27-31, 2012, Baltimore, MD.

Cutter, C. A. (1904). Rules for a dictionary catalog (4th ed., rewritten). Washington: Government Printing Office. UNT Digital Library. Retrieved from: http://digital.library.unt.edu/ark:/67531/metadc1048/.

Europeana Data Model Mapping Guidelines v1.0.1. (2012). Europeana. [24/04/2012] Section 4.1 Properties for an agent (edm:Agent). Retrieved from http://pro.europeana.eu/documents/900548/ea68f42d-32f6-4900-91e9-ef18006d652e

Foucault, M. (1977). What is an author? In Language, Counter-Memory, Practice, trans, by D. F. Bouchard and S. Simon. Ithaca, NY: Cornell University Press.

IFLA Study Group on the Functional Requirements for Bibliographic Records. (1997, 2009 rev.). Functional requirements for bibliographic records: Final report. International Federation of Library Associations and Institutions. Retrieved from: http://www.ifla.org/VII/s13/frbr/.

MARC 21 Format for Authority Data. (2013, April). 1999 updates through 16. Library of Congress. Retrieved from http://www.loc.gov/marc/authority/ecadhome.html

Niu, J. (2013). Evolving landscape in name authority control. Cataloging \& Classification Quarterly, 51(4), 404-419.

Oliver, C. (2010). Introducing RDA: A guide to the basics. Chicago: American Library Association.

Patton, G. E. (Ed.). (2009). Functional requirements for authority data: A conceptual model. IFLA Working Group on Functional Requirements and Numbering of Authority Records (FRANAR). Germany: K. G. Saur.

$\begin{array}{llll}\text { Person. } & \text { (n.d.). DBpedia. } & \text { Retrieved }\end{array}$ http://mappings.dbpedia.org/server/ontology/classes/Person

Smiraglia, R. P., \& Lee, H. (2012). Rethinking the authorship principle. Library Trends, 61(1), 35-48.

Smiraglia, R. P., Lee, H., Olson, H. A. (2011). Epistemic presumptions of authorship. In iConference 2011, \& ACM Digital Library. Proceedings of the 2011 iConference. New York, NY: ACM.

Svenonius, E. (2000). The intellectual foundation of information organization. Cambridge, Massachusetts: MIT Press.

The American Civil War: Letters and Diaries. (2001). Alexandria, Va.: Alexander Street Press. Retrieved from http://solomon.cwld.alexanderstreet.com/cwld.help.html

Tillett, B. (2003). What is FRBR?: A conceptual model for the bibliographic universe. Library of Congress Cataloging Distribution Service. Retrieved from http://www.loc.gov/cds/downloads/FRBR.PDF.

VIAF. (2012). Data source. VIAF. Retrieved from http://viaf.org/viaf/data/.

Wilson, A. (1999). Foucault on the "question of the author:" A critical exegesis. Modern Language Review, 99(2), 339-63.

Wilson, A. (2012). What is a text? Studies in History and Philosophy of Science, 43, 341-358.

Yee, M. M. (2005). FRBRization: A method for turning online public finding lists into online public catalogs. Information Technology \& Libraries, 24(2), 77-95. 